\title{
Shigekazu Nagata \\ Human autoimmune lymphoproliferative syndrome, a defect in the apoptosis-inducing Fas receptor: A lesson from the mouse model
}

Received December 24, 1997 / Accepted January 5, 1998

\begin{abstract}
The immune response is regulated not only by the proliferation, differentiation, and activation of cells, but also by programmed cell death, called apoptosis. Fas ligand expressed in activated $\mathrm{T}$ cells binds to its receptor, Fas, and induces apoptosis in target cells. Two mouse mutations that cause autoimmune disease, $\operatorname{lpr}$ (lymphoproliferation) and gld (generalized lymphoproliferative disease), are mutations in Fas and FasL genes, respectively. Human patients showing phenotypes (Canale-Smith syndrome or autoimmune lymphoproliferative syndrome) similar to those in $l p r$ mice also carry mutations in Fas. This is a good example of a case in which the identification of a mouse mutation has led to the understanding of a human disease.
\end{abstract}

Key words Apoptosis - Autoimmune disease - CanaleSmith syndrome $\cdot$ Fas $\cdot$ Loss-of-function mutation

\section{Fas ligand and Fas}

Cellular proliferation, differentiation, and apoptosis are regulated by a family of proteins called cytokines. Fas ligand (FasL) is a cytokine that belongs to the tumor necrosis factor (TNF) family (Nagata 1997; Nagata and Golstein 1995). FasL is predominantly expressed in activated $T$ lymphocytes and natural killer (NK) cells, and works as one of the effector molecules of these cytotoxic cells. FasL is synthesized as a type II membrane protein, and its extracellular region of about 150 amino acids is well conserved $(20 \%-25 \%)$ among members of the TNF family. A metalloproteinase called TACE (TNF alpha converting enzyme) cleaves membrane-associated TNF to produce a soluble TNF (Black et al. 1997; Moss et al. 1997). Similarly, membrane-bound FasL undergoes metalloproteinasemediated proteolytic cleavage to generate a soluble form of

S. Nagata $(\square)$

Department of Genetics, Osaka University Medical School, 2-2

Yamada-oka, Suita, Osaka 565, Japan

Tel: +81-6-879-3310; Fax: +81-6-879-3319

e-mail: nagata@genetic.med.osaka-u.ac.jp this cytokine (Tanaka et al. 1996). The membrane-bound FasL is more active than soluble FasL in inducing apoptosis, suggesting that FasL works locally via cell-cell interactions under physiological conditions, and that the purpose of shedding FasL is to attenuate the process. The functional soluble form of human FasL exists as a trimer, suggesting that membrane-bound FasL also has the potential to form a trimeric structure.

Fas (also known as APO-1 or CD95), the receptor for FasL, is a type I membrane protein, and is expressed rather ubiquitously in various tissues (Nagata 1997; Nagata and Golstein 1995). Fas is a member of the TNF receptor (TNFR) family, which includes two TNFRs (TNFR1 and TNFR2), DR3 (death receptor-3), DR-4, and DR-5. The extracellular region of the TNF receptor family members carries 2-6 repeats of a cysteine-rich subdomain that has about $25 \%$ similarity among its members. In contrast, there is little similarity among the cytoplasmic regions of the TNFR family members, except for Fas, TNFR1, DR-3, and DR-4. Binding of FasL to Fas, or cross-linking Fas with agonistic antibodies induces apoptosis in Fas-bearing cells (Itoh et al. 1991; Trauth et al. 1989; Yonehara et al. 1989). TNF induces apoptosis mainly through TNFR1, although it can also activate the transcription factor NF- $x \mathrm{~B}$ through this receptor (Vandenabeele et al. 1995). The presence of a homologous domain (about 80 amino acids) in the cytoplasmic regions of Fas and TNFR1 suggests that this region is responsible for transducing the death signal. In fact, mutational analyses of Fas and TNFR1 indicated that this is the case, and this domain has been designated a death domain (Itoh and Nagata 1993; Tartaglia et al. 1993). DR-3 and DR4 also carry a death domain, and can transduce the apoptotic signal under some circumstances.

Fas and TNFR1 must be oligomerized to be activated. Xray diffraction analysis of the TNF $\beta$-TNF receptor complex has indicated that a TNF $\beta$ trimer forms a complex with three TNF receptor molecules (Banner et al. 1993). This suggests that TNF induces trimerization of its receptor. The similarity between the structures of FasL and TNF, and between Fas and the TNF receptors suggest that FasL also induces trimerization of Fas, and that the trimerized cyto- 
plasmic region then transduces the signal. Fas-mediated apoptosis does not require RNA or protein synthesis (Itoh et al. 1991; Yonehara et al. 1989), suggesting that all the components necessary for apoptotic signal transduction are already present in growing cells, and that Fas activation just triggers this machinery. An adaptor molecule called FADD (Fas-associated protein with death domain) or MORT1, which contains a death domain at its C-terminus (Boldin et al. 1995; Chinnaiyan et al. 1996), is recruited to Fas upon its activation (Kischkel et al. 1995) and binds to Fas via interactions between the death domains. The $\mathrm{N}$-terminal region [termed the death-effector domain (DED) or MORT1 domain] is responsible for the downstream signal transduction and binds caspase 8 (Boldin et al. 1996; Muzio et al. 1996). Caspase 8 carries two DED/MORT1 domains in its $\mathrm{N}$-terminal region, through which it binds FADD/MORT1. Thus, the Fas oligomerization induced by the binding of FasL results in the oligomerization of caspase 8, which probably causes the self-activation of its protease domain.

Caspases are a family of cysteine proteases consisting of two large (p17) and two small (p10) subunits, which are generated by the proteolytic cleavage of a larger precursor (a zymogen). The caspase family is comprised of at least 10 members, which are divided into three subgroups based on their substrate specificity (Alnemri et al. 1996; Thornberry et al. 1997). All caspases cleave their substrates after aspartic acid, and cause apoptosis when overexpressed in cells. Inhibitors of caspase 1 or caspase 3 block Fas-induced apoptosis, which suggests that both caspase 1- and caspase 3like proteases are involved in Fas-mediated apoptosis (Enari et al. 1996). Monitoring the protease activity with fluorescent substrates specific for caspase 1 and caspase 3 demonstrates that a caspase 1-like protease is transiently activated, whereas the activation of a caspase 3 -like protease gradually increases during Fas-induced apoptosis. The activation of the caspase 3-like protease is dependent on the activation of a caspase 1-like protease, indicating that these proteases are sequentially activated. It is likely that other members of the caspase family are also activated in the cascade, and these members cleave their "death substrates" such as lamin, actin, poly(ADP-ribose) polymerase, rhoGDI, SREBP, and DNA-dependent protein kinase, to cause the apoptotic morphological changes (Martin and Green 1995). We have recently identified a caspase-activated DNase (CAD) that is localized to the cytoplasm of growing cells (Enari et al. 1998). CAD seems to exist as a complex with ICAD (an inhibitor of CAD), which can be cleaved by caspase 3 (Sakahira et al. 1998). Thus, apoptotic stimuli activate caspase, which cleaves and thus inactivates ICAD. ICAD inactivation allows the release of $\mathrm{CAD}$, which can then enter nuclei to cleave the chromosomal DNA.

\section{Ipr and gld}

The mouse mutations $\operatorname{lpr}$ (lymphoproliferation) and gld (generalized lymphoproliferative disease) are autosomal recessive mutations located on mouse chromosomes 19 and
1, respectively (Cohen and Eisenberg 1991). There is another allelic mutation in the $l p r$ locus, which was discovered in the CBA/k1 mouse strain (Matsuzawa et al. 1990). Since the mutated mice $\left(l p r^{c g} /+, g l d /+\right)$ that are heterozygous for $g l d$ show a weak phenotype, the mutation was designated as $l p r^{c g}$ (for $l p r$ complementing gld). Allen et al. (1990) performed a series of bone marrow transplantations among $l p r, g l d$, and wild-type mice to establish the relationship between these defects. These analyses indicated that $l p r$ and gld are mutations in two different proteins and, more specifically, that gld is a mutation of a soluble or membrane-bound cytokine, while $l p r$ is a mutation of its receptor. As described below, we have identified the mutations in Fas and FasL in $l p r$ and gld mice (Takahashi et al. 1994; Watanabe-Fukunaga et al. 1992), thus verifying this proposal.

MRL-lpr or -gld mice develop lymphadenopathy and splenomegaly, and produce large amounts of antibodies, including anti-DNA antibody and rheumatoid factor (Cohen and Eisenberg 1991). The mice die of nephritis or arthritis at approximately 5 months of age. Lymphocytes accumulate in the lymph nodes and spleen of $l p r$ or $g l d$ mice, and this accumulation can be prevented by neonatal thymectomy. The accumulated lymhocytes express the Tcell marker Thy-1, and the B-cell marker B220. These cells also express a rearranged $\mathrm{T}$-cell receptor, but not a rearranged $\operatorname{IgG}$ gene. Although $\mathrm{CD} 4$ and $\mathrm{CD} 8$, which are usually expressed in mature $\mathrm{T}$ cells, are not expressed in these lymphocytes, it is likely that they are derived from mature single positive $\mathrm{CD} 4^{+} \mathrm{CD} 8^{-}$or $\mathrm{CD} 4^{-} \mathrm{CD} 8^{+} \mathrm{T}$ cells by suppressing the expression of CD4 or CD8.

The Fas gene maps to a location near the lpr locus of mouse chromosome 19, and Northern blot hybridization indicated that $l p r$ mice express very little Fas mRNA (Watanabe-Fukunaga et al. 1992). The Fas chromosomal gene is more than $70 \mathrm{~kb}$ in length and is split by 8 introns, whereas the mutated gene in $l p r$ mice has an early transposable element (ETn), similar to an endogenous retrovirus, inserted into intron 2 (Fig. 1a) (Adachi et al. 1993). Since the ETn carries poly(A) adenylation signals (AATAAA) in its long terminal repeat (LTR) sequences, it was assumed that the Fas transcript prematurely terminates in intron 2 and is aberrantly spliced. In fact, small mRNAs coding for exons 1 and 2 have been found in the thymus and liver of $l p r$ mice. These results indicate that transcription of the gene encoding Fas is impaired in $l p r$ mice. However, the inhibition of expression is not complete, as demonstrated by the presence of full-length Fas mRNA, albeit at a low level, in the thymus and liver of $l p r$ mice, indicating that $l p r$ is a leaky mutation. Unlike the $l p r$ strain, $l p r^{c g}$ mice express full-length Fas mRNA as abundantly as wild-type mice (WatanabeFukunaga et al. 1992). However, the mRNA carries a point mutation ( $\mathrm{T}$ to $\mathrm{A}$ ) in the middle of the Fas cytoplasmic region (Watanabe-Fukunaga et al. 1992). This mutation results in an amino acid change, from isoleucine to asparagine (Fig. 1a), and abolishes the ability of Fas to transduce the apoptotic signal.

The murine gene for FasL maps close to the At-3 gene on chromosome 1 (Takahashi et al. 1994), where the gld muta- 
Fig. 1a,b Mutations of genes encoding Fas and FasL in $l p r$ and gld mice. a Structure of the gene encoding Fas, and its mutation in $l p r$ and $l p r^{c g}$ mice. Structure of the gene encoding mouse $\mathrm{Fas}$ is shown schematically (top). The middle part indicates the insertion of an early transposable (ETn) element in intron 2 of the Fas gene. The ETn carryies two poly(A) adenylation sites. The drawing at bottom shows a point mutation of Fas protein in $l p r^{c g}$ mice. The shaded area indicates the death domain. b Structure of FasL and its point mutation in $\mathrm{gld}$ mice. The structure of FasL is shown schematically (top). $C Y T$, $T M$ and EXT represent the cytoplasmic, transmembrane, and extracellular regions, respectively. The point mutation of FasL in gld mice is indicated by an arrow
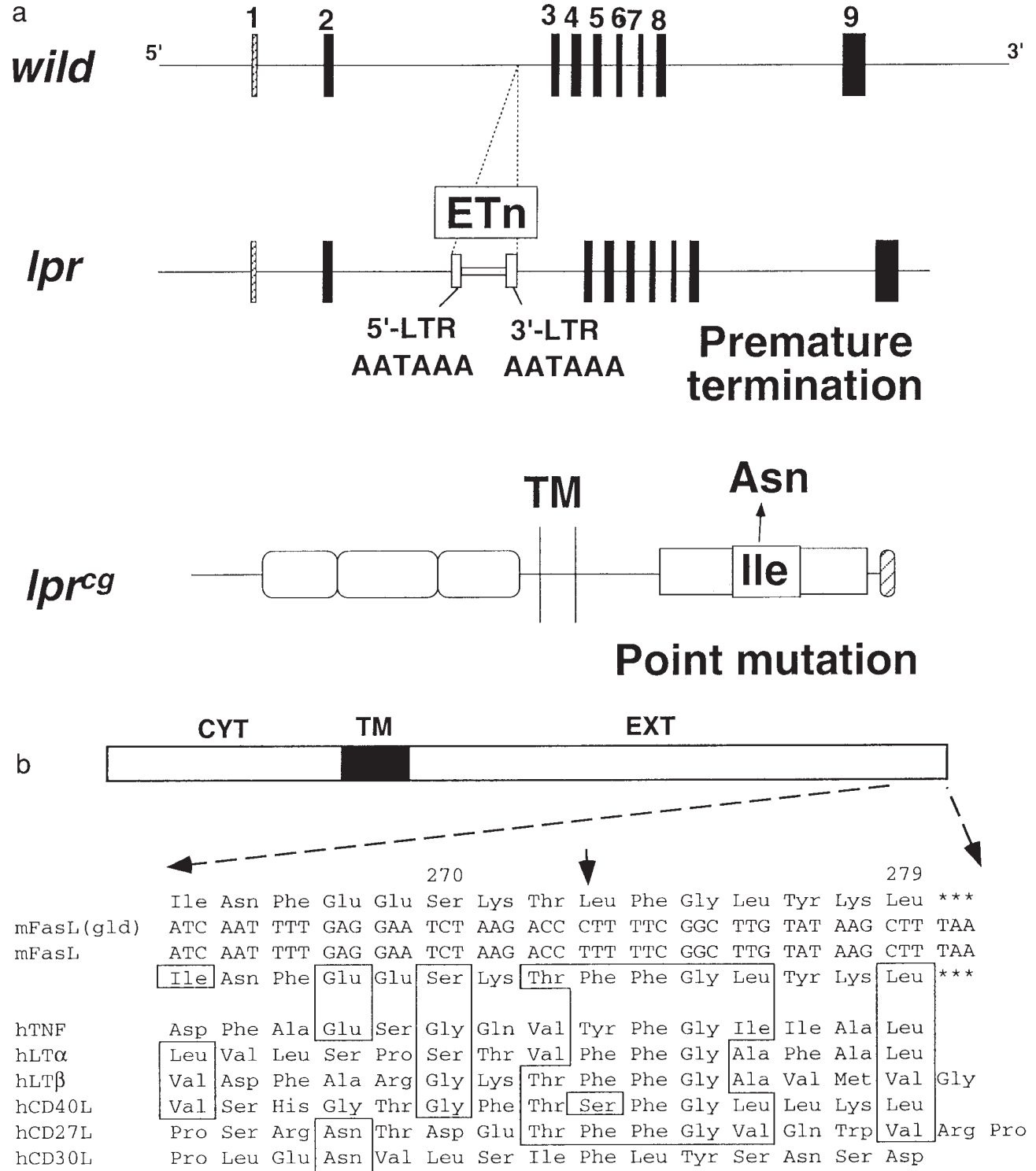

tion is localized. It has been shown that gld mice carry a point mutation near the $\mathrm{C}$-terminus of the coding region for FasL (Fig. 1b) (Takahashi et al. 1994). This mutation results in the replacement of phenylalanine with leucine, and abolishes the ability of FasL to bind to Fas. These results indicate that mouse mutations $l p r$ and gld are loss-of-function mutations of Fas and FasL, respectively. Fas-null mice, established by gene targeting (Adachi et al. 1995), also show lymphadenopathy and splenomegaly which are more pronounced than in mice carrying the leaky lpr mutation, further confirming the above conclusion.

\section{Physiological roles of Fas-induced apoptosis}

Lymphocytes, which are responsible for removing virally infected and cancerous cells, die at various stages of their development. Most immature T cells are useless (due to incorrect rearrangement of the T-cell receptor) or potentially detrimental (self-reactive) to the organism. More than $95 \%$ of the thymocytes that immigrate into the thymus are eliminated by positive and negative selection during their development. In the periphery, mature $\mathrm{T}$ cells that recognize self antigens are also deleted (peripheral clonal deletion). When mature $\mathrm{T}$ cells encounter target cells, they are activated to proliferate. However, after the activated T cells accomplish their task, they must be removed to avoid accumulation.

Mature $\mathrm{T}$ cells from $l p r$ or gld mice do not die upon activation (Russell et al. 1993). When T-cell hybridomas are activated in the presence of a Fas-neutralizing molecule, they do not die (Brunner et al. 1995; Dhein et al. 1995; Ju et al. 1995). These results indicate that Fas is involved in the activation-induced suicide of $\mathrm{T}$ cells, i.e., in the downregulation of the immune response (Nagata and Golstein 
1995). Peripheral clonal deletion may also be mediated by the Fas system, because the cells to be deleted in this process are activated by interactions with the cells expressing self antigens. Thymocytes abundantly express Fas, and they are sensitive to Fas-induced apoptosis. However, thymic clonal deletion is apparently normal in mice lacking the functional Fas system (lpr, gld or Fas-null mice) (Singer and Abbas 1994). These results suggest that Fas is not involved in the deletion process in the thymus, although one cannot rule out the possibility that this process is mediated by redundant mechanisms or is modulated by Fas/FasL system (Castro et al. 1996).

In addition to $T$ cells, the Fas-deficient mice accumulate $B$ cells and have elevated levels of immunoglobulins of various classes, which include anti-ssDNA and anti-dsDNA antibodies (Cohen and Eisenberg 1991), suggesting an involvement of the Fas system in the deletion of activated or autoreactive B lymphocytes. In fact, the immunization of mice with antigens rapidly induces Fas expression in germinal centers. Furthermore, the activation of naive B cells through CD40 sensitizes them to Fas-mediated apoptosis, while their co-stimulation through CD40 and the Ig receptor makes them resistant (Rothstein et al. 1995). Although these results suggest that FasL-expressing $\mathrm{T}$ cells kill the Fas-expressing activated $\mathrm{B}$ cells, the precise mechanism and physiological role of Fas in the deletion of B cells remains to be studied.

\section{Fas mutations in human patients}

The Canale-Smith syndrome, also called human lymphoproliferative syndrome and autoimmunity or autoimmune lymphoproliferative syndrome, is a rare disease that causes lymphadenopathy in children (Canale and Smith 1967). Patients with the syndrome show lymphadenopathy, hepatosplenomegaly, and hypergammaglobulinemia within the first two years of life. Some patients also show autoimmune diseases such as hemolytic anemia, thrombocytopenia, and neutropenia, resulting from the production of autoantibodies against red blood cells and platelets. The cells accumulated in the lymph nodes and spleen comprise a usual population of nonmalignant $\mathrm{T}$ cells that have characteristics of $\mathrm{CD}^{-} \mathrm{CD}^{-}$and $\mathrm{TcR}^{+}$cells. These cells express high levels of HLA-DR and IL-2 receptor $\alpha$-chain, suggesting that they are chronically activated T cells. Since these phenotypes are similar to those found in lpr or gld mice, many groups looked for abnormalities in the Fas gene of these patients. In fact, to date, seventeen alleles for Fas mutations accompanying this syndrome have been identified in France, USA, Italy, and Japan (Bettinardi et al. 1997; Drappa et al. 1996; Fisher et al. 1995; Kasahara et al. 1997; Le Deist et al. 1996; RieuxLaucat et al. 1995; Sneller et al. 1997).

Among these mutant alleles in the human Fas gene, thirteen are mutations in the coding sequence (Fig. 2a), while four are mutations in the splice junctions (Fig. 2b). Deletion and insertion mutations, as well as non-sense mutations in the extracellular and cytoplasmic regions of the
Fas gene result in the genes that code for truncated Fas molecules. One point mutation is found in the extracellular region, which probably abolishes its ligand-binding activity. Five point mutations are in the Fas cytoplasmic region (Fig. 3), each of which causes a nonconservative amino acid replacement, and may abolish the ability of Fas to recruit the signal-transducing adaptor FADD. Two mutations are in splice junctions in intron 3, and these cause aberrant splicing of the region of the Fas transcript that codes for the soluble form of Fas. Other mutations in either intron 6 or 7 produce a Fas protein that lacks most of its cytoplasmic region.

The mouse lpr mutation is recessive, and mice carrying the heterozygous $l p r$ or $l p r^{c g}$ mutation do not show the mutant phenotype (Cohen and Eisenberg 1991). Accordingly, there are three examples of human patients carrying homozygous Fas mutations. Patients with a deletion mutation (Del-291) and a splice mutation in intron 2 carry the mutation as two alleles with identical lesions (Bettinardi et al. 1997; Kasahara et al. 1997). These patients are born to parents who are first or second cousins, and the parents are heterozygous for the same mutation. In another example, three siblings of one family carry a mutation of "compound homozygocity," in which children carry the R-105 to W-105 mutation in one allele, and the Y-216 to C-216 mutation in the other allele. These mutations are inherited from the mother and father, respectively. All other patients seem to carry a heterozygous mutation in the Fas gene. Because Fas must be trimerized to transduce the signal, these molecules, which are truncated or bear a mutation in the cytoplasmic region, are postulated to behave in a dominant-negative manner (Fisher et al. 1995). Fas truncated in the extracellular region (specifically truncated after exon 3 ) is postulated to work as a soluble form of Fas that can neutralize FasL. Although the above explanation is probably correct, it does not explain why abnormal phenotypes are not seen in the fathers or mothers of the patients, who also carry a heterozygous mutation in the Fas gene. The patients who show the disease phenotypes may carry mutations in other complementing genes. Alternatively, Fas may be required only during the perinatal period in humans.

\section{Conclusions}

The Canale-Smith syndrome results from a congenital mutation and is difficult to cure. Identifying a Fas mutation in patients suffering from this syndrome may help to establish proper treatment for them. In mice, Fas seems to be involved in the homeostasis of $\mathrm{T}$ cells at a certain stage of development. Thus, splenoectomy at two weeks of age markedly retards lymphoproliferation (Smathers et al. 1984), and treatment of the affected animals at the age of 19 weeks with drugs such as DIAM4 reduces the autoimmune disease (In et al. 1990). If Fas is required primarily in early human development, surgery on the enlarged lymph nodes and spleen may cure the disease in human patients. 
As mentioned above, the $\mathrm{T}$ cells that accumulate in $l p r$ mice and human patients are activated $\mathrm{T}$ cells, and they express a high level of Fas ligand. When the bone-marrow cells of $l p r$ mice are transferred to wild-type mice, the recipient mice undergo graft-versus-host-disease-like wasting syndrome, and quickly die (Theofilopoulos et al. 1985). The disease is due to FasL expressed in T cells derived from $l p r$ mice, which induces massive apoptosis in various tissues, because many cells in the wild-type recipients express func- tional Fas. We now know that many families carry a heterozygous mutation in the Fas gene without any obvious abnormal phenotype. If the other allele of the Fas gene is sporadically mutated in $\mathrm{T}$ lymphocytes, those $\mathrm{T}$ lymphocytes carrying the homozygous mutation may cause tissue destruction and wasting syndrome.

Identification of FasL and Fas as a death factor and its receptor, has led us to the discovery that the murine $l p r$ and gld defects are mutations in the genes encoding Fas and

a

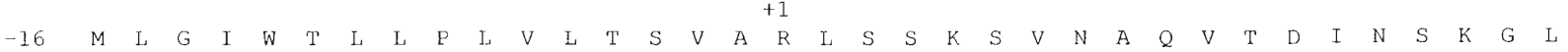
ATGCTGGGCATCTGGACCCTCCTACCTCTGGTTC'PTACGTCTGTTGCTAGATTATCGTCCAAAAGTGTTAATGCCAAGTGACTGACATCAACTCCAAGGGATTG

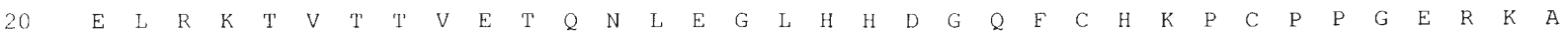
GAATTGAGGAAGACTGTTACTACAGTTGAGACTCAGAACTTGGAAGGCCTGCATCATGATGGCCAATTCTGCCATAAGCCCTGTCCTCCAGGTGAAAGGAAAGCT

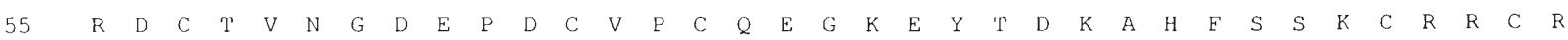
AGGGACTGCACAGTCAATGGGGATGAACCAGACTGCGTGCCCTGCCAAGAAGGGAAGGAGTACACAGACAAAGCCCA'T'T'T'TTTCCAAATGCAGAAGATGTAGA ----GGGGATAACCAGA-..--(one bp deletion) G D K

AGGGACTGAACA (non-sense mutation)

$\mathrm{R}$ D *

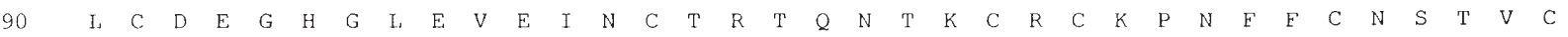
TTGTGTGATGAAGGACATGGCTTAGAAGTGGAAATAAACTGCACCCGGACCCAGAATACCAAGTGCAGATGTAAACCAAACTTTTTTTGTAACTCTACTGTATGT ---ACCTGGACCCAG (missense mutation) T $\mathrm{W}$ T $Q$

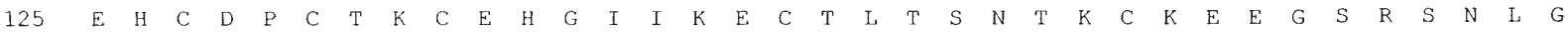
GAACACTGTGACCCTTGCACCAAATGGAACATGGAATCATCAAGGAATGCACACTCACCAGCAACACCAAGTGCAAAGAGGAAGGATCCAGATCTAACTTGGGG

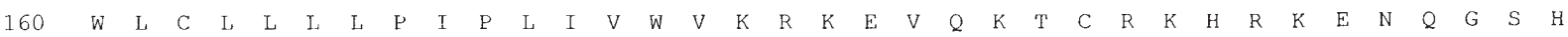
TGGCTTTGTCTTCTTCTTTTGCCAATTCCACTAATTGTTTGGGTGAAGAGAAAGGAAGTACAGAAAACATGCAGAAAGCACAGAAAGGAAAACCAAGGTTCTCAT

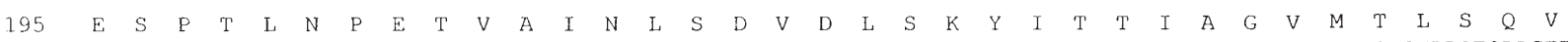
GAATCTCCAACCTTAAATCCTGAAACAGTGGCAATAAATTTATCTGATGTGACTTGAGTAAATATATCACCACTATTGCTGGAGTCATGACACTAAGTCAAGTT

- -ATGCCACTA----

M P L (missense mutation)

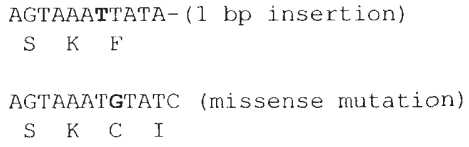

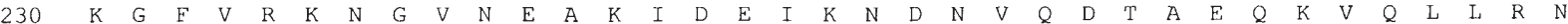
AAAGGCTT'T GTCGAAAGAATGGTGTCAATGAAGCCAAAATAGATGAGATCAAGAATGACAATGTCCAAGACACAGCAGAACAGAAAGTTCAACTGCTTCGTAAT CAAGACAGCAGAA--- (2 bp deletion)

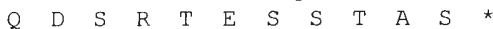
--- GAATAGAAAGTP---

$E \star$ (non-sense mutation) TTTGTTTGAAAGAATGGT (nonsense mutation)

ATATATGAGATC (missense mutation)

$\begin{array}{llll}I & Y & E & I\end{array}$ $\mathrm{F} \quad \mathrm{V}$ *

GAAGACAAAATAGAT (missense mutation)

$\begin{array}{lllll}E & D & K & I & D\end{array}$

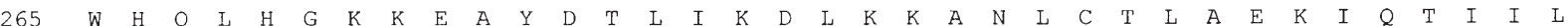
TGGCATCAACTTCATGGAAAGAAAGAAGCGTATGACACATTGATTAAAGATCTCAAAAAAGCCAATCTTTGTACTCTTGCAGAGAAAATTCAGACTATCATCCTC -..-TTTGTACT $(290$ bp deletion)---

AAAAGTCAGAC (missense mutation)

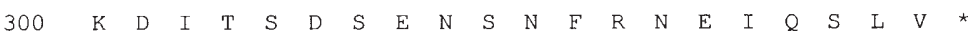
$\mathrm{K} S \mathrm{~S} \quad \mathrm{~T}$

AAGGACATTACTAGTGACTCAGAAAATTCAAACTTCAGAAATGAAATCCAAAGCTTGGTCTA

Fig. 2a,b Mutant alleles in human Fas gene in patients of Canale-Smith syndrome. a The nucleotide and amino acid sequences of the coding region of the human Fas gene are shown. Thirteen mutant alleles found in human patients of Canale-Smith syndrome are indicated. b Four mutant alleles (bold) at splicing junction of the human Fas chromosomal gene. The nucleotide sequence mutated in patients of CanaleSmith syndrome is shown with the corresponding wild-type sequence 
Fig. 2 Continued

b

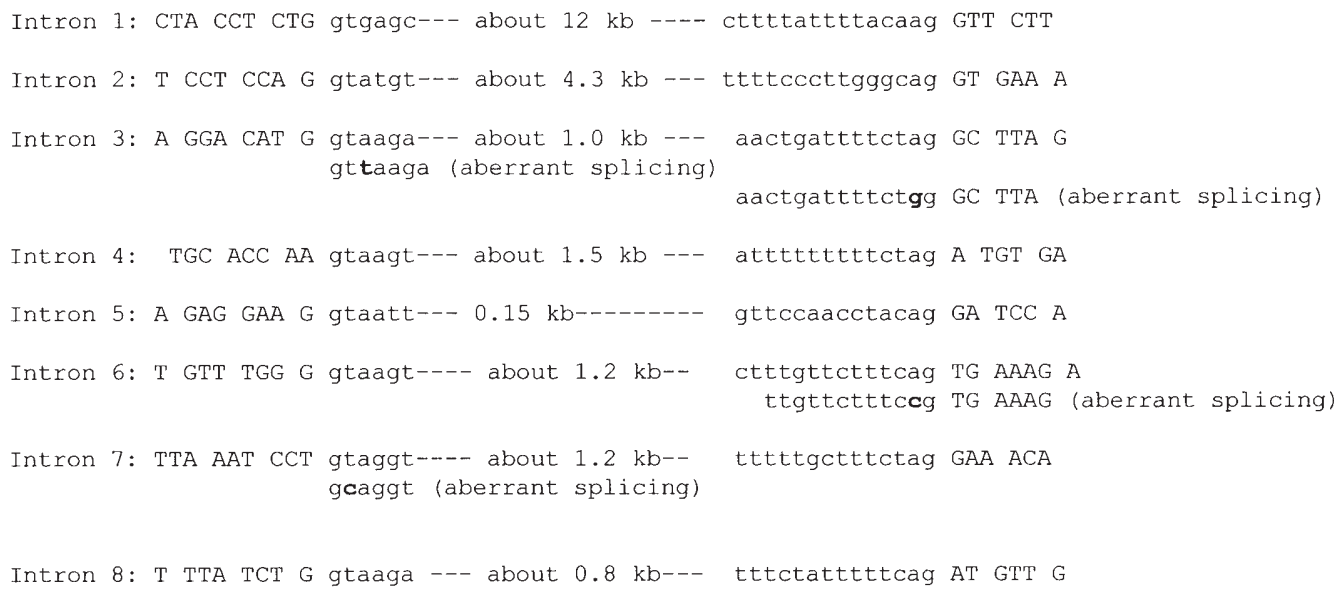

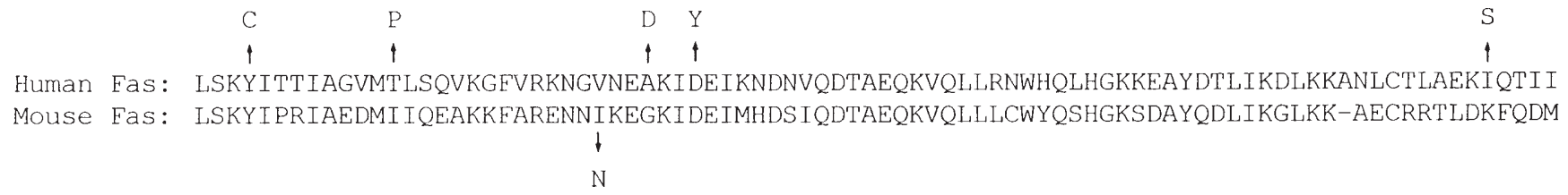

Fig. 3 Point mutations in the death domain of the Fas cytoplasmic region. The amino acid sequences of the death domain of human and mouse Fas are aligned. Point mutations found in human patients of

FasL. This discovery has now led us to the identification of the molecular basis of a human disease. This is a prime example of a case in which a mouse disease model directly led to the understanding of analogous human diseases. Many groups are currently establishing mice lacking genes involved in apoptotic signal transduction. Phenotypes seen in these mice would certainly contribute to our knowledge of human diseases.

\section{References}

Adachi M, Watanabe-Fukunaga R, Nagata S (1993) Aberrant transcription caused by the insertion of an early transposable element in an intron of the Fas antigen gene of lpr mice. Proc Natl Acad Sci USA 90:1756-1760

Adachi M, Suematsu S, Kondo T, Ogasawara J, Tanaka T, Yoshida N, Nagata S (1995) Targeted mutation in the Fas gene causes hyperplasia in the peripheral lymphoid organs and liver. Nature Genet 11:294-300

Allen RD, Marshall JD, Roths JB, Sidman CL (1990) Differences defined by bone marrow transplantation suggest that lpr and gld are mutations of genes encoding an interacting pair of molecules. J Exp Med 172:1367-1375

Alnemri ES, Livingston DJ, Nicholson DW, Salvesen G, Thornberry NA, Wong WW, Yuan J (1996) Human ICE/CED-3 protease nomenclature. Cell 87:171

Banner DW, D'Arcy A, Janes W, Gentz R, Schoenfeld H-J, Broger C, Loetscher H, Lesslauer W (1993) Crystal structure of the soluble human $55 \mathrm{kd}$ TNF receptor-human TNF $\beta$ complex: implication for TNF receptor activation. Cell 73:431-445

Bettinardi A, Brugnoni D, Quiròs-Roldan E, Malagoli A, La Grutta S, Correra A, Notarangelo LD (1997) Missense mutations in the Fas
Canale-Smith syndrome are indicated in the upper part, while that found in $l p r^{c g}$ mice is shown in the lower part

gene resulting in autoimmune lymphoproliferative syndrome: a molecular and immunological analysis. Blood 89:902-909

Black RA, Rauch CT, Kozlosky CJ, Peschon JJ, Slack JL, Wolfson MF, Castner BJ, Stocking KL, Reddy P, Srinivasan S, Nelson N, Boiani N, Schooley KA, Gerhart M, Davis R, Fitzner JN, Johnson RS, Paxton RJ, March CJ, Cerretti DP (1997) A metalloproteinase disintegrin that releases tumour-necrosis factor- $\alpha$ from cells. Nature 385:729-733

Boldin MP, Varfolomeev EE, Pancer Z, Mett IL, Camonis JH, Wallach $\mathrm{D}$ (1995) A novel protein that interacts with the death domain of Fas/APO1 contains a sequence motif related to the death domain. J Biol Chem 270:7795-7798

Boldin MP, Goncharov TM, Goltsev YV, Wallach D (1996) Involvement of MACH, a novel MORT1/FADD-interacting protease, in Fas/APO-1- and TNF receptor-induced cell death. Cell 85:803815

Brunner T, Mogil RJ, LaFace D, Yoo NJ, Mahboubi A, Echeverri F, Martin SJ, Force WR, Lynch DH, Ware CF, Green DR (1995) Cellautonomous Fas (CD95)/Fas-ligand interaction mediates activationinduced apoptosis in T-cell hybridomas. Nature 373:441-444

Canale V, Smith C (1967) Chronic lymphadenopathy simulating malignant lymphoma. J Pediatr 70:891-899

Castro JE, Listman JA, Jacobson BA, Wang Y, Lopez PA, Ju S, Finn PW, Perkins DL (1996) Fas modulation of apoptosis during negative selection of thymocytes. Immunity 5:617-627

Chinnaiyan AM, Tepper CG, Seldin MF, O'Rourke K, Kischkel FC, Hellbardt S, Krammer PH, Peter ME, Dixit VM (1996) FADD/ MORT1 is a common mediator of CD95(Fas/APO-1) and tumor necrosis factor-induced apoptosis. J Biol Chem 271:4961-4965

Cohen PL, Eisenberg RA (1991) Lpr and gld: single gene models of systemic autoimmunity and lymphoproliferative disease. Annu Rev Immunol 9:243-269

Dhein J, Walczak H, Bäumler C, Debatin K-M, Krammer PH (1995) Autocrine T-cell suicide mediated by APO-1/(Fas/CD95). Nature 373:438-441

Drappa J, Vaishnaw AK, Sullivan KE, Chu JL, Elkon KB (1996) Fas gene mutations in the Canale-Smith syndrome, an inherited 
lymphoproliferative disorder associated with autoimmunity. N Engl J Med 335:1643-1649

Enari M, Talanian RV, Wong WW, Nagata S (1996) Sequential activation of ICE-like and CPP32-like proteases during Fas-mediated apoptosis. Nature 380:723-726

Enari M, Sakahira H, Yokoyama H, Okawa K, Iwamatsu A, Nagata S (1998) A caspase-activated DNase that degrades DNA during apoptosis and its inhibitor ICAD. Nature 391:43-50

Fisher GH, Rosenberg FJ, Straus SE, Dale JK, Middelton LA, Lin AY, Strober W, Lenardo MJ, Puck JM (1995) Dominant interfering Fas gene mutations impair apoptosis in a human autoimmune lymphoproliferative syndrome. Cell 81:935-946

In S, Dueymes M, Appolinaire-Pilipenko S, Sournies F, Labarre JF, Fournine GJ (1990) Treatment of end-stage MRL-lpr/lpr mouse lupus disease by a cyclophosphazene-derived drug and by cyclosporin A. J Clin Lab Immunol 32:85-90

Itoh N, Nagata S (1993) A novel protein domain required for apoptosis: mutational analysis of human Fas antigen. J Biol Chem 268:10932-10937

Itoh N, Yonehara S, Ishii A, Yonehara M, Mizushima S, Sameshima M, Hase A, Seto Y, Nagata S (1991) The polypeptide encoded by the cDNA for human cell surface antigen Fas can mediate apoptosis. Cell 66:233-243

Ju S-T, Panka DJ, Cui H, Ettinger R, El-Khatib M, Sherr DH, Stanger BZ, Marshak-Rothstein A (1995) Fas (CD95)/FasL interaction required for programmed cell death after T-cell activation. Nature 373:444-448

Kasahara Y, Wada T, Niida Y, Yachie A, Seki H, Ishida Y, Sakai T, Koizumi F, Koizumi S, Miyawaki T, Taniguchi N (1998) Novel Fas (CD95/APO-1) mutation in infants with lymphoproliferative disorders. Int Immunol, in press

Kischkel FC, Hellbardt S, Behrmann I, Germer M, Pawlita M, Krammer PH, Peter ME (1995) Cytotoxicity-dependent APO-1 (Fas/CD95)-associated proteins from a death-inducing signaling complex (DISC) with the receptor. EMBO J 14:5579-5588

Le Deist F, Emile JF, Rieux-Laucat F, Benkerrou M, Roberts I, Brousse N, Fischer A (1996) Clinical, immunological, and pathological consequences of Fas-deficient conditions. Lancet 348:719-723

Martin S, Green D (1995) Protease activation during apoptosis: Death by a thousand cuts. Cell 82:349-352

Matsuzawa A, Moriyama T, Kaneko T, Tanaka M, Kimura M, Ikeda H, Katagiri T (1990) A new allele of the lpr locus, $l p r^{c g}$, that complements the gld gene in induction of lymphadenopathy in the mouse. $\mathrm{J}$ Exp Med 171:519-531

Moss ML, Jin S-LC, Milla ME, Burkhart W, Carter HL, Chen W-J, Clay WC, Didsbury JR, Hassler D, Hoffman CR, Kost TA, Lambert MH, Leesnitzer MA, McCauley P, McGeehan G, Mitchell J, Moyer M, Pahel G, Rocque W, Overton LK, Schoenen F, Seaton T, Su J-L, Warner J, Willard D, Becherer JD (1997) Cloning of a disintegrin metalloproteinase that processes precursor tumor necrosis factor a. Nature 385:733-736

Muzio M, Chinnaiyan AM, Kischkel FC, O'Rourke K, Shevchenko A, Ni J, Scaffidi C, Bretz JD, Zhang M, Gentz R, Mann M, Krammer PH, Peter ME, Dixit VM (1996) FLICE, a novel FADDhomologous ICE/CED-3-like protease, is recruited to the CD95 (Fas/APO-1) death-inducing signaling complex. Cell 85:817-827

Nagata S, Golstein P (1995) The Fas death factor. Science 267:14491456
Nagata S (1997) Apoptosis by death factor. Cell 88:355-365

Rieux-Laucat F, Le Deist F, Hivroz C, Roberts IAG, Denatin KM, Fischer A, de Villarty JP (1995) Mutations in Fas associated with human lymphoproliferative syndrome and autoimmunity. Science 268:1347-1349

Rothstein TL, Wang JKM, Panka DJ, Foote LC, Wang Z, Stanger B, Cui H, Ju S-T, Marshak-Rothstein A (1995) Protection against Fasdependent Th1-mediated apoptosis by antigen receptor engagement in B cells. Nature 374:163-165

Russell JH, Rush B, Weaver C, Wang R (1993) Mature T cells of autoimmune lpr/lpr mice have a defect in antigen-stimulated suicide. Proc Natl Acad Sci USA 90:4409-4413

Sakahira H, Enari M, Nagata S (1998) Cleavage of CAD inhibitor in CAD activation and DNA degradation during apoptosis. Nature 391:96-99

Singer GG, Abbas AK (1994) The Fas antigen is involved in peripheral but not thymic deletion of $\mathrm{T}$ lymphocytes in $\mathrm{T}$ cell receptor transgenic mice. Immunity 1:365-371

Smathers PA, Santoro TJ, Chused TM, Reeves JP, Steinberg AD (1984) Studies of lymphoproliferation in MRL-lpr/lpr mice. J Immunol 133:1955-1961

Sneller MC, Wang J, Dale JK, Strober W, Middelton LA, Choi Y, Fleisher TA, Lim MS, Jaffe ES, Puck JM, Lenardo MJ, Straus SE (1997) Clinical, immunologic, and genetic features of an autoimmune lymphoproliferative syndrome associated with abnormal lymphocyte apoptosis. Blood 89:1341-1348

Takahashi T, Tanaka M, Brannan CI, Jenkins NA, Copeland NG, Suda T, Nagata S (1994) Generalized lymphoproliferative disease in mice, caused by a point mutation in the Fas ligand. Cell 76:969976

Tanaka M, Suda T, Haze K, Nakamura N, Sato K, Kimura F, Motoyoshi K, Mizuki M, Tagawa S, Ohga S, Hatake K, Drummond AH, Nagata S (1996) Fas ligand in human serum. Nature Med 2: 317-322

Tartaglia LA, Ayres TM, Wong GHW, Goeddel DV (1993) A novel domain within the $55 \mathrm{kd}$ TNF receptor signals cell death. Cell 74 : 845-853

Theofilopoulos AN, Balderas RS, Gozes Y, Aguado MT, Hang L, Morrow PR, Dixon FJ (1985) Association of lpr gene with graft-vs.host disease-like syndrome. J Exp Med 162:1-18

Thornberry NA, Rano TA, Peterson EP, Rasper DM, Timkey T, Garcia-Calvo M, Houtzager VM, Nordstrom PA, Roy S, Vaillancourt JP, Chapman KT, Nicholson DW (1997) A combinatorial approach defines specificities of members of the caspase family and granzyme B. J Biol Chem 272:17907-17911

Trauth BC, Klas C, Peters AMJ, Matzuku S, Möller P, Falk W, Debatin K-M, Krammer PH (1989) Monoclonal antibody-mediated tumor regression by induction of apoptosis. Science 245:301-305

Vandenabeele P, Declercq W, Beyaert R, Fiers W (1995) Two tumor necrosis factor receptors: structure and function. Trends Cell Biol 5: 392-399

Watanabe-Fukunaga R, Brannan CI, Copeland NG, Jenkins NA, Nagata S (1992) Lymphoproliferation disorder in mice explained by defects in Fas antigen that mediates apoptosis. Nature 356:314317

Yonehara S, Ishii A, Yonehara M (1989) A cell-killing monoclonal antibody (anti-Fas) to a cell surface antigen co-downregulated with the receptor of tumor necrosis factor. J Exp Med 169:1747-1756 